\title{
A utilização da comunicação digital pelos professores do curso de Relações Públicas
}

\section{The use of digital communication by teachers of the course of Public Relations}

\author{
Maristela Jurkevicz*, Joaquim Escola*, Regiane Ribeiro** \\ *Universidade de Trás-Montes e Alto Douro, **PUC-SP
}

\begin{abstract}
Resumo
Apresentamos alguns dos dados obtidos nos questionários aplicados junto aos professores que ministram aulas no curso de Relações Públicas e alunos das últimas séries, da Universidade Estadual de Londrina, situada no norte do Paraná, no Brasil. O objetivo desta etapa foi o de identificar os aspectos do cenário digital no curso selecionado para investigação e a concepção sobre as Relações Públicas neste novo ambiente, sob o ponto de vista destes dois sujeitos (professores e alunos). Trata-se de uma parcela da investigação realizada na tese de doutoramento em Ciências da Educação desenvolvida na Universidade de Trás-os-Montes e Alto Doro (UTAD) PT.

Palavras-chave: ensino superior de relações públicas, sociedade da informação e do conhecimento, tecnologias da informação e conhecimento, formação profissional.
\end{abstract}

\begin{abstract}
We present some of the data obtained in the questionnaires applied along to teachers who teach classes in the course of Public Relations and alumni of the last series, the Universidade Estadual de Londrina, situated in the North of Paraná, in Brazil. The objective of this step was to identify aspects of the digital setting in the selected course for research and design about public relations in this new environment, from the point of view of these two subjects (teachers and students). This is a portion of the research conducted in the doctoral thesis in education developed at the University of Trás-os-Montes e Alto Doro (UTAD) PT.

Keywords: higher education public relations, information and knowledge society, information and knowledge, vocational training.
\end{abstract}

O objetivo de nossa tese a ser apresentada junto à Universidade de Trás-os-Montes e Alto Douro em Portugal, como parte do doutoramento em Ciências da Eduação foi pesquisar, avaliar e propor alternativa de arquitetura curricular para o Projeto Pedagógico de Curso, da habilitação em Relações Públicas da Universidade Estadual de Londrina, contemplando o uso das Tecnologias da Informação e Comunicação (TIC), a partir de literatura específica e das Diretrizes Curriculares Nacionais. Nossa pretensão foi refletir sobre os desafios impostos pela Sociedade da Informação e do Conhecimento ao ensino superior e mais especificamente à graduação de Relações Públicas. Além do novo contexto digital, o curso de Relações Públicas da Universidade Estadual de Londrina, foco deste estudo, tinha a necessidade de atender as Diretrizes Curriculares Nacionais de 2013. Portanto, um momento oportuno para revisar sua matriz curricular e propor novas metodologias de ensino, como a que foi sugerida ao final do estudo, com a introdução da utilização de metodologias ativas preferencialmente com o uso das TIC no ensino.

No presente artigo apresentamos alguns dos resultados da análise dos dados quantitativos, recolhidos por meio das seguintes fontes de pesquisa, os professores que ministram aulas no Curso de Relações Públicas da Universidade Estadual de Londrina e alunos das terceiras e quartas séries do curso. Para o alcance do objetivo proposto reunimos os dados obtidos por meio dos questionários disponibilizados on-line para os professores e no blog criado especialmente para os alunos. Para a análise das informações utilizamos uma abordagem qualitativa, procurando proceder à interpretação e discussão dos aspectos mais relevantes. De acordo com Gil (2002, p.84), “[...] consiste na organização das idéias com vista em atender aos objetivos ou testar as hipóteses formuladas no início da pesquisa. Assim, cabe nesta etapa estruturar logicamente o trabalho para que ele possa ser entendido como unidade dotada de sentido". Ainda nesta etapa destaca Amado \& Vieira (2013, p. 378) são combinadas a "informação prévia, explicitação e domínio de conceitos, trabalho sistemático, rigor metodológico e criatividade", transformando os dados recolhidos em dados com significado, despontando a figura do investigador. E nas palavras de Denzin \& Lincoln (2003), o pesquisador qualitativo será um “confeccionador de colchas” (p.5), procurando, costurar, editar e reunir recortes da realidade, ou seja, reagrupar um conjunto de representações que demonstrem as especificidades de uma situação complexa.

\section{Objetivos}

Em nosso estudo de caso apresentado na tese, a nosso unidade de análise foi o curso de Relações Públicas da Universidade Estadual de Londrina, com seu projeto pedagógico, grupo de professores e alunos, no período de 2013 a 2016. 
Neste recorte apresentamos os resultados obtidos nos questionários disponibilizados on line para os professores do Curso de Relações Públicas da UEL e nos questionários colocados no blog especialmente criados para os alunos das terceiras e quarta séries. O objetivo desta etapa foi: Identificar os aspectos do cenário digital no curso selecionado para investigação e a concepção sobre as Relações Públicas neste novo ambiente. $\mathrm{O}$ objetivo foi desdobrado em dimensões, cada uma com mais aspectos a serem identificados, de acordo com a fonte selecionada para coleta de informações, conforme apresentamos em seguida. No questionário disponibilizado para os professores investigamos cinco dimensões: 1) Perfil dos Professores, 2) Formação Profissional, 3) Planejamento de Ensino, 4) Utilização das TIC no ensino e, 5) Diretrizes Curriculares Nacionais. Selecionamos para este nosso recorte destacar as seguintes dimensões com alguns de seus aspectos, a dimensão 1, apresentando o perfil dos Professores do curso; a dimensão 5, evidenciando a utilização das TIC no ensino. Já no questionário direcionado para os alunos, foram analisadas quatro dimensões: 1) Perfil dos alunos, 2) Preparação para o uso das TIC, 3) Planejamento de ensino do professor, 4) Utilização das TIC no ensino pelos professores. Optamos por apresentar os seguintes aspectos: na dimensão 1 o perfil dos alunos das terceiras e quarta séries do curso de Relações Públicas da UEL, na dimensão 4 , identificar a percepção dos alunos quanto a utilização das TIC pelos professores do curso.

\section{Método}

$\mathrm{Na}$ fase quantitativa de nosso estudo selecionamos a utilização de inquérito por meio de questionários. Para Lobiondo-Wood e Haber (2001) os questionários são instrumentos de registro escritos e planejados para pesquisar dados de sujeitos, por meio de questões relacionadas a conhecimentos, atitudes, crenças e sentimentos. São considerados instrumentos com bom potencial de investigação em educação de acordo com Tuckman (2000), na medida em que possibilitam transformar em dados a informação comunicada diretamente por um sujeito. Na visão de Vilelas (2009) a finalidade do inquérito por questionário consiste em obter, de maneira sistemática e ordenada, a informação, a respeito da população/amostra selecionada para o estudo, referentes às variáveis que são objeto de análise. Nossa pretensão com a utilização deste instrumento está relacionada com os seguintes objetivos indicados por Quivy e Campenhoudt (2003), buscar compreender os modos de vida, comportamentos, valores e opiniões de determinados sujeitos, bem como apreender melhor a análise de um fenômeno social, a partir de informações recebidas dos indivíduos da população selecionada para o estudo e também com a visão de Vilelas (2009), obter informações a respeito de nossa temática junto aos professores e alunos do curso de RP da UEL.

\section{Participantes}

Participaram desta fase de nossa investigação 22 professores de um total de 28 que atuavam na área no ano de 2015. Foram selecionados como fonte de coleta de dados os professores que ministraram aulas nos cursos de
Relações Públicas no ano de 2015, das seguintes áreas: Relações Públicas (10), Jornalismo (2), Teoria da Comunicação (6) e de outros departamentos da Universidade (10), totalizando 28 professores. Destes, 22 responderam o questionário enviado on line, correspondendo a uma participação de 78,6\% da população. O perfil dos professores correspondia as questões de número 1 do Questionário aplicado junto a eles nos meses de outubro e novembro de 2015, e continha 8 perguntas. Selecionamos algumas delas para apresentar as características gerais do grupo (sexo, idade, formação na graduação, tempo de serviço, tempo de serviço na docência e regime de trabalho). Participaram da investigação um maior percentual de mulheres $59,1 \%$, seguido de $40,9 \%$ de homens, com a maioria entre 45 e 55 anos $(31,8 \%)$ a 56 ou mais $(27,3 \%)$. Constatamos que os respondentes eram em sua maioria 7 (32\%) formados em Relações Públicas, seguidos de formados em jornalismo $3(13,5 \%)$ e turismo $2(9 \%)$. Os demais índices (7) correspondem aos professores de Teoria da Comunicação e de outros departamentos participantes da amostra (Administração, Ciências Contábeis, Ciências Sociais, Filosofia, Letras, Matemática e Psicologia), sendo que três deles não responderam esta questão. Quanto ao tempo de serviço a maioria $(36,4 \%)$ está entre 21 e 30 anos atuando no mercado e entre 11 e 20 anos $(27,3 \%)$, totalizando $(63,7 \%)$, sendo que a maior parte deles $(22,7 \%)$ assinalou entre 21 e 30 anos deste tempo, prestando serviços na UEL, seguidos de $(13,6 \%)$ entre 11 e 20 anos. Portanto, inferimos que uma grande parte dos professores tem sua atuação marcada na academia, com pouca experiência no mercado de trabalho formal, fora da docência. E como último dado do perfil a grande maioria $(81,8 \%)$ tem 40 horas com Tempo Integral de Dedicação Exclusiva (TIDE), podendo dedicar maior tempo para a área do Ensino de Graduação.

Os alunos que foram selecionados como fontes de informação são da $3^{\mathrm{a}}$ e $4^{\mathrm{a}}$ séries do curso de RP dos turnos matutino e noturno. Com uma participação de 58 alunos dos 66 do total desta população, representando 83,3\%. As questões referentes ao perfil constavam no questionário on line disponibilizado por meio de um blog construído pela investigadora, com o número 1 , contendo 5 alternativas. As questões que possibilitaram o delineamento do perfil foram as seguintes: gênero, idade, estado civil, série e identificação da localidade de origem. As características do perfil dos alunos possibilitam as seguintes leituras, a maioria deles $(79,3 \%)$ são do sexo feminino, com idade entre 20 e 34 anos $(93,1 \%)$ e a grande maioria de solteiros $(98,3 \%)$. Do total da amostra $\mathrm{N}=58$ participaram 32 alunos $(55,2 \%)$ da $4^{\mathrm{a}}$ série e 26 alunos $(44,8 \%)$ da $3^{\mathrm{a}}$ série, provenientes em grande parte da cidade de Londrina $(58,6 \%)$ e $29,3 \%$ do interior de São Paulo. 
Tabela 1 .

Caracterização dos Alunos constituintes da investigação

\begin{tabular}{|c|c|c|}
\hline 1. Perfil do aluno & Fr. & $\%$ \\
\hline \multicolumn{3}{|l|}{ 1.1.Genêro } \\
\hline Feminino & 46 & $79.3 \%$ \\
\hline Masculino & 12 & $20.7 \%$ \\
\hline \multicolumn{3}{|l|}{1.2 Idade } \\
\hline Entre 16 e 19 & 2 & $3.4 \%$ \\
\hline Entre 20 e 34 & 54 & $93.1 \%$ \\
\hline Entre 35 e 44 & 1 & $1.7 \%$ \\
\hline Entre 45 e 55 & 1 & $1.7 \%$ \\
\hline $56 \mathrm{ou}+$ & 0 & $0 \%$ \\
\hline \multicolumn{3}{|l|}{ 1.3 Estado civil } \\
\hline Solteiro (a) & 57 & $98.3 \%$ \\
\hline Casado (a) & 1 & $1.7 \%$ \\
\hline Separado (a) & 0 & $0 \%$ \\
\hline Viúvo (a) & 0 & $0 \%$ \\
\hline União estável & 0 & $0 \%$ \\
\hline \multicolumn{3}{|l|}{ 1.4 Série que está cursando } \\
\hline $3^{\mathrm{a}}$ série & 26 & $44.8 \%$ \\
\hline $4^{\mathrm{a}}$ série & 32 & $55.2 \%$ \\
\hline \multicolumn{3}{|c|}{ 1.5 Proveniente que qual localidade } \\
\hline Londrina & 34 & $58.6 \%$ \\
\hline Outras cidades do paraná & 3 & $5.2 \%$ \\
\hline Interior de são paulo & 17 & $29.3 \%$ \\
\hline \multirow[t]{2}{*}{ Outros } & 4 & $6.9 \%$ \\
\hline & $\mathrm{N}=22$ & \\
\hline
\end{tabular}

\section{Resultados}

Procuramos examinar na dimensão - Utilização das TIC no ensino de RP, em que medida os professores se utilizam de computadores e Internet em suas atividades de ensino; quais os serviços mais utilizados e o quanto estimulam os alunos a utilizarem as TIC em sala de aula. E com relação aos alunos, buscamos dimensionar em que medida percebem a utilização de computadores e Internet pelos professores, em suas atividades de ensino; quais os serviços mais utilizados e o quanto são estimulados pelos seus professores a utilizarem as TIC em sala de aula. Elaboramos dois gráficos (gráfico 1 e 2) e duas tabelas (tabela 2,3) para a análise destas questões.

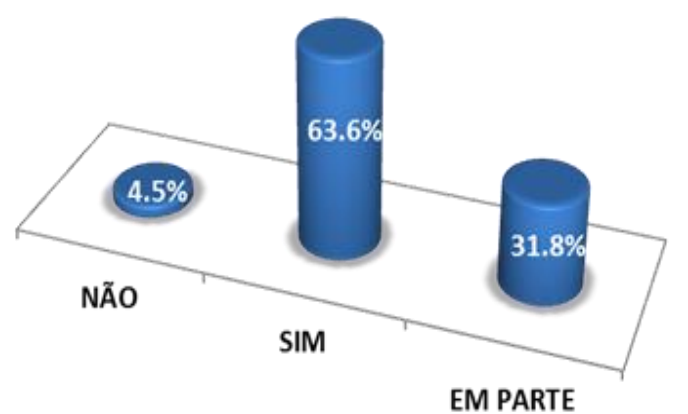

Gráfico 1. Utilização dos serviços da Internet nas disciplinas que ministra em RP - Professores

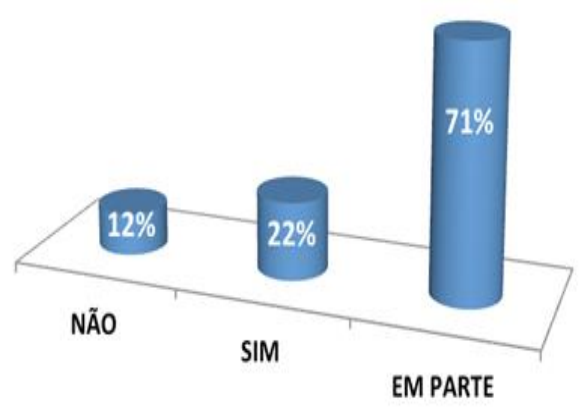

Gráfico 2. Percepção de alunos sobre a utilização dos serviços da Internet nas disciplinas oferecidas pelo curso de RP - Alunos

Os gráficos nos mostram uma relativa incorporação dos serviços da Internet pelos professores do curso, com $63,6 \%$ afirmando o seu uso e 3,8\% mencionando um uso parcial. No ponto de vista dos alunos pesquisados existe também um entendimento de razoável inserção das TIC no ensino, mas seus apontamentos estão invertidos em relação aos professores, considerando uma utilização parcial da Internet pelos seus professores com $73 \%$ e $22 \%$ indicando como efetiva. 
Tabela 2.

Frequência de utilização dos serviços da Internet no semestre letivo pelos professores

\begin{tabular}{|c|c|c|c|}
\hline \multicolumn{2}{|c|}{ UTILIZAÇÃOO DAS TIC NO ENSINO } & fr. & $\%$ \\
\hline \multicolumn{4}{|c|}{ Frequência de utilização dos serviços da internet no semestre letivo } \\
\hline \multirow{6}{*}{ CORREIO ELETRÔNICO } & Não conheço & 2 & $9.5 \%$ \\
\hline & 1x a cada semestre & 0 & $0 \%$ \\
\hline & 1xa cada bimestre & 0 & $0 \%$ \\
\hline & 1x por mês & 4 & $19 \%$ \\
\hline & 1x a cada 15 dias & 4 & $19 \%$ \\
\hline & Diariamente ou pelo menos 1 x por semana & 11 & $52.4 \%$ \\
\hline \multirow{6}{*}{ FÓRUM } & Não conheço & 8 & $38.1 \%$ \\
\hline & 1xa cada semestre & 6 & $28.6 \%$ \\
\hline & 1x a cada bimestre & 2 & $9.5 \%$ \\
\hline & $1 x$ por mês & 2 & $9.5 \%$ \\
\hline & 1x a cada 15 dias & 0 & $0 \%$ \\
\hline & Diariamente ou pelo menos 1 x por semana & 3 & $14.3 \%$ \\
\hline \multirow{6}{*}{ CHAT } & Não conheço & 9 & $42.9 \%$ \\
\hline & 1xa cada semestre & 7 & $33.3 \%$ \\
\hline & 1xacada bimestre & 2 & $9.5 \%$ \\
\hline & 1x por mês & 1 & $4.8 \%$ \\
\hline & $1 \times$ a cada 15 dias & 1 & $4.8 \%$ \\
\hline & Diariamente ou pelo menos $1 \mathrm{x}$ por semana & 1 & $4.8 \%$ \\
\hline \multirow{6}{*}{ SITES, BLOGS, WIKIS } & Não conheço & 3 & $14.3 \%$ \\
\hline & Ix a cada semestre & 4 & $19 \%$ \\
\hline & Ix a cada bimestre & 1 & $4.8 \%$ \\
\hline & Ix por mês & 0 & $0 \%$ \\
\hline & $1 \mathrm{x}$ a cada 15 dias & 6 & $28.6 \%$ \\
\hline & Diariamente ou pelo menos 1 x por semana & 7 & $33.3 \%$ \\
\hline \multirow{6}{*}{ VIDEOCONFEREANCIA } & Não conheço & 12 & $57.1 \%$ \\
\hline & 1x a cada semestre & 7 & $33.3 \%$ \\
\hline & 1x a cada bimestre & 1 & $4.8 \%$ \\
\hline & 1x por mês & 0 & $0 \%$ \\
\hline & $1 \mathrm{x}$ a cada 15 dias & 0 & $0 \%$ \\
\hline & Diariamente ou pelo menos $1 x$ por semana & 1 & $4.8 \%$ \\
\hline \multirow{6}{*}{ REDES SOCIAIS } & Não conheço & 6 & $28.6 \%$ \\
\hline & Ix a cada semestre & 4 & $19 \%$ \\
\hline & 1x a cada bimestre & 0 & $0 \%$ \\
\hline & 1x por mês & 1 & $4.8 \%$ \\
\hline & $1 x$ a cada 15 dias & 3 & $14.3 \%$ \\
\hline & Diariamente ou pelo menos $1 \mathrm{x}$ por semana & 7 & $33.3 \%$ \\
\hline OUTROS & & - & - \\
\hline
\end{tabular}

Tabela 3.

Frequência de utilização dos serviços da Internet no semestre letivo na percepção dos alunos

\begin{tabular}{|c|c|c|c|}
\hline \multicolumn{2}{|c|}{ UTIUZAÇÃO DAS TIC PELOS PROFESSORES DO CURSO } & fr. & $\%$ \\
\hline \multicolumn{4}{|c|}{ Frequênciade utilização dos serviços da internet pelos professores no semestre letivo } \\
\hline \multirow{7}{*}{ CORREIO ELETRÔNICO } & Não conheço & 1 & $19 \%$ \\
\hline & Nẵo utilizam & 5 & $9.4 \%$ \\
\hline & 1x a coda semestre & 2 & $3.8 \%$ \\
\hline & Ix a coda bimestre & 2 & $3.8 \%$ \\
\hline & Xx por mês & 3 & $5.7 \%$ \\
\hline & 1x a coda 15 dias & 13 & $24.5 \%$ \\
\hline & Diariamente ou pelo menos $1 x$ por semana & 27 & $50.9 \%$ \\
\hline \multirow{7}{*}{ FÓRUM } & Não conheço & 6 & $11.3 \%$ \\
\hline & Nắo utilizam & 41 & $77.4 \%$ \\
\hline & 1x a coda semestre & 2 & $3.8 \%$ \\
\hline & Ix a coda bimestre & 2 & $3.8 \%$ \\
\hline & Xx por mês & 2 & $3.8 \%$ \\
\hline & 1x a coda 15 dias & 0 & $0 \%$ \\
\hline & Diariamente ou pelo menos $1 x$ por semana & 0 & $0 \%$ \\
\hline \multirow{7}{*}{ CHAT } & Não conheço & 4 & $7.7 \%$ \\
\hline & Năo utilizam & 36 & $69.2 \%$ \\
\hline & Ix a coda semestre & 4 & $7.7 \%$ \\
\hline & 1x a coda bimestre & 3 & $5.8 \%$ \\
\hline & Ix por mês & 2 & $3.8 \%$ \\
\hline & 1x a cada 15dias & 0 & $0 \%$ \\
\hline & Diariamente ou pelo menos $1 x$ por semana & 3 & $5.8 \%$ \\
\hline \multirow{7}{*}{ SITES, BLOGS, WKIS } & Não conheço & 3 & $5.7 \%$ \\
\hline & Năo utilizam & 12 & $226 \%$ \\
\hline & Ix a coda semestre & 12 & $226 \%$ \\
\hline & Ix a coda bimestre & 8 & 15.196 \\
\hline & Ix por mês & 7 & $13.2 \%$ \\
\hline & 1x a ada 15 dias & 5 & $9.4 \%$ \\
\hline & Diariamente ou pelo menos $1 x$ por semana & 6 & $11.3 \%$ \\
\hline \multirow{7}{*}{ VIDEOCONFERÊNCIA } & Não conheço & 5 & $9.4 \%$ \\
\hline & Năo utilizam & 40 & $75.5 \%$ \\
\hline & Ix a coda semestre & 4 & $7.5 \%$ \\
\hline & Ix a coda bimestre & 1 & $19 \%$ \\
\hline & Ix por mês & 3 & $5.7 \%$ \\
\hline & 1x a cada 15 dias & 0 & $0 \%$ \\
\hline & Diariamente ou pelo menos 1x por semana & 0 & $0 \%$ \\
\hline \multirow{7}{*}{ REDESSOCIAIS } & Não conheço & 1 & $19 \%$ \\
\hline & Não utilizam & 11 & $20.8 \%$ \\
\hline & Ix a coda semestre & 12 & $2266 \%$ \\
\hline & Ix a coda bimestre & 6 & $11.3 \%$ \\
\hline & 1x por mês & 7 & $13.2 \%$ \\
\hline & 1x a coda 15 dias & 9 & $17 \%$ \\
\hline & Diariamente ou pelo menos $1 x$ por semana & 7 & $13.2 \%$ \\
\hline OUTROS & & - & - \\
\hline \multicolumn{4}{|c|}{$\mathrm{N}=58$} \\
\hline
\end{tabular}

Três serviços da Internet foram os mais indicados pelos professores como os mais utilizados no semestre letivo em suas disciplinas, com seus alunos: o correio eletrônico com um percentual de 52,4\% de uso semanal, $19 \%$ quinzenal e $19 \%$ mensal; os sites, blogs e wikis com um percentual de $61,9 \%$ em três intervalos, $1 \mathrm{x}$ por semana (33\%), 1x cada 15 dias $(28,6 \%)$ e $1 \mathrm{x}$ cada semestre (19\%); e as redes sociais com as indicações $1 \mathrm{x}$ por semana $(33,3 \%) ; 1 \mathrm{x}$ a cada dia 15 dias $(14,3 \%)$; e $1 \mathrm{x}$ cada semestre (19\%), sendo que $28,6 \%$ deles, afirmaram não conhecerem ou não utilizaram esta modalidade com os seus alunos.

Estes mesmos serviços foram percebidos pelos seus alunos como os mais utilizados, contudo os percentuais variaram um pouco. $\mathrm{O}$ correio eletrônico teve um total de $75,4 \%$ nos intervalos semanal $(50,9 \%)$ e quinzenal 
(24,5\%); os sites, blogs e wikis tiveram uma pontuação dispersa em toda escala totalizando $71,6 \%$, iniciando com o intervalo semestral $(22,6 \%)$, no bimestre $(15,1 \%)$, no mês $(13,2 \%)$, na semana $(11,3 \%)$ e a cada 15 dias $(9,4 \%)$. Ainda $22,6 \%$ confirmaram a não utilização deste serviço pelos seus professores. E as redes sociais também receberam uma pontuação dispersa em toda a escala, com um percentual de $77,3 \%$ nos índices $1 \mathrm{x}$ cada semestre $(22,6 \%) ; 1 \mathrm{x}$ a cada 15 dias $(17 \%)$; $1 \mathrm{x}$ por mês $(13,2 \%)$; $1 \mathrm{x}$ por semana $(13,2 \%)$ e $1 \mathrm{x}$ cada bimestre $(11,3 \%)$. Uma parcela dos alunos $(20,8 \%)$ admitiu a não utilização deste serviço pelos seus professores.

Entre os serviços menos utilizados pelos professores estão a videoconferência com um percentual de $57,1 \%$ na categoria não conhece/não utiliza contra 33,3 \% dos professores que utilizam $1 \mathrm{x}$ a cada semestre. Os chats apareceram com 42,9\% no item não conhece/não utiliza, seguidos de $33,3 \%$ de professores que afirmaram utilizar $1 \mathrm{x}$ a cada semestre. $\mathrm{E}$ o fórum com um maior porcentagem na categoria não conhece/não utiliza $(38,1 \%)$, seguidos do item $1 \times$ a cada semestre $(28,6 \%)$ e $1 \mathrm{x}$ por semana $(14,3 \%)$. Os alunos foram mais incisivos, afirmando a não utilização destes serviços pelos professores, à videoconferência com $75,5 \%$ de indicação como não utilizada; o fórum com $77,4 \%$ nesta mesma categoria, e o chat com 69,2\%.

\section{Discussão e Conclusão}

As TIC no curso de RP da UEL estão relativamente incorporadas no ensino e nas atividades desenvolvidas pelos seus professores e percebidas pelos alunos como parcialmente inseridas nas rotinas e práticas em seu percurso no programa curricular. Os professores tem se utilizado com mais intensidade dos serviços básicos da Internet como o correio eletrônico e com um razoável uso de sites, blogs e redes sociais com seus alunos, indicando um avanço no incremento de pesquisas. Na pesquisa qualitativa alguns dos professores relataram o uso das redes sociais para compartilhamento de arquivos e matérias complementares aos assuntos dados em aula, e para disseminação dos trabalhos realizados pelos alunos. Os alunos confirmaram esta utilização das TIC, porém os percentuais tiveram uma variação para menos, perceberam uma utilização com uma frequência menor do que apontado pelos professores.

Concordando com Moran (2007), podemos afirmar que infinitas são as possibilidades de opções que a Internet apresenta, trazendo uma melhor qualidade ao planejamento das práticas do professor, incluindo o auxílio na seleção e inovação de suas metodologias e recursos didáticos de ensino. A Internet pode ajudar o professor a preparar melhor a sua aula, a ampliar as formas de ensinar, a modificar o processo de avaliação e de comunicação com o aluno e com os seus colegas.

As tecnologias podem ser excelentes recursos se os professores as conhecerem e utilizarem de forma adequada, tendo o domínio e conhecimento de seu uso, assim como reconhecer as formas de trabalhar com as TIC no ensino superior, e especificamente nas disciplinas da grade curricular oferecidas pelo curso de RP, uma vez que as tecnologias "representam, aproximam, facilitam o acesso do aluno à realidade que se aprende, mas estes, não têm sentido nenhum por si só, a não ser pelo papel que se lhes concede dentro do currículo, ou seja, em relação com as necessidades, prioridades, objetivos, conteúdos e atividades que se trabalham numa determinada área" (Raposo Rivas, 2002, p. 50).

A integração curricular das TIC envolve diversas competências tecnológicas, técnicas, metodológicas e atitudinais que se interligam numa teia complexa de relações. De acordo com Gomes (2014): "Só com uma atitude positiva face à utilização das tecnologias em sala de aula, com o desenvolvimento de competências que permitam aos docentes usar adequadamente as ferramentas disponíveis ao serviço das aprendizagens, de uma reflexão sistemática sobre as práticas de utilização das tecnologias e o seu impacto nas aprendizagens dos alunos se poderá caminhar para uma efetiva integração curricular das TIC". (p. 305).

Para atender em parte esta necessidade é que fizemos ao final de nossa tese uma proposição para novos usos metodológicos com o uso das TIC, na tentativa de suprir esta lacuna que aparece na preparação dos professores e assim colaborar para a formação profissional das relações-públicas no cenário digital.

\section{Referências}

Amado, J., \&Vieira, C. C. (2013). Apresentação dos dados: interpretação e teorização. In Amado, J. (Coord.). Manual de investigação qualitativa em educação (pp. 377- 417). Coimbra: Imprensa da Universidade de Coimbra.

Denzin, N. K., \& Lincoln, Y. S. (Orgs.) (2003). Collecting and interpreting qualitative materials. Thousand Oaks: Sage Publications.

Gil, A. C. (2002). Como elaborar projetos de pesquisa (4a ed.). São Paulo: Atlas.

Gomes, A. C. (2014). As tecnologias da informação $e$ comunicação no $1^{o}$. Ciclo do ensino básico: possibilidades e integração. Tese de doutorado, Universidade de Trás-os-Montes e Alto Douro, Vila Real, Portugal.

Lobiondo-Wood, G., \& Haber, J. (2001). Pesquisa em enfermagem: métodos, avaliação crítica e utilização. Rio de Janeiro: Guanabara Koogan.

Moran, J. M. (2007). Novas tecnologias e mediação pedagógica (13a ed.). Campinas: Papirus.

Quivy, R., \& Campenhoudt, V. (2003). Manual de investigação em ciências sociais (3a ed.). Lisboa: Gradiva.

Raposo-Rivas, M. (2002). Novas tecnoloxías aplicadas à educación: aspectos técnicos e didácticos. Vigo: Universidad de Vigo, Portugal.

Tuckman, B. W. (2000). Manual de investigação em educação: como conceber e realizar o processo de investigação em educação. Lisboa: Fundação Calouste Gulbenkian.

Vilelas, J. (2009). Investigação: o processo de construção do conhecimento. Lisboa: Sílabo. 